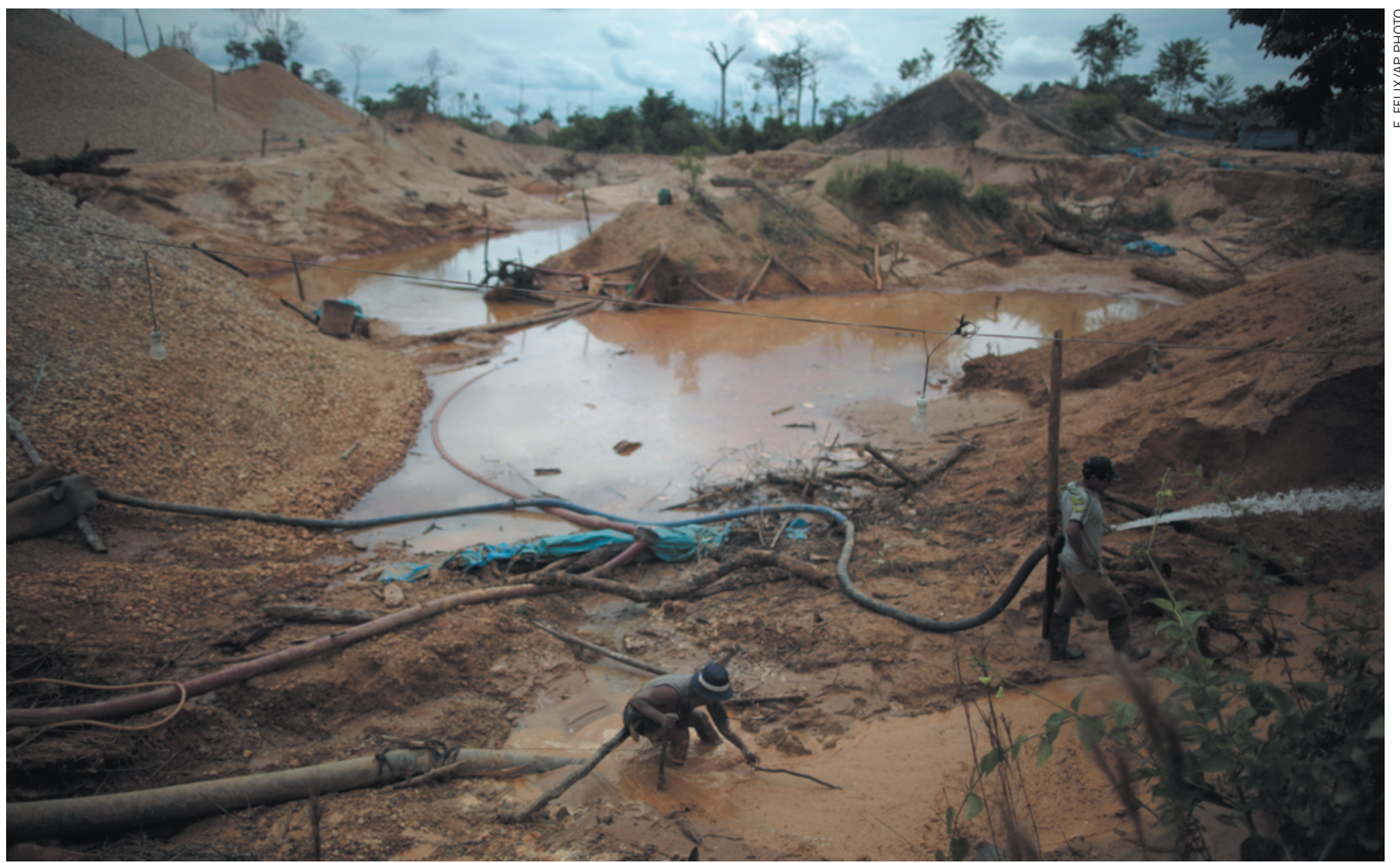

Many unregulated gold mines in Madre de Dios, Peru, leave a trail of environmental devastation in their wake.

\title{
ENVIRONMENT
}

\section{Peru battles the golden curse of Madre de Dios}

\section{Attempts to reduce the environmental and health impacts of mining cause unrest.}

\section{BY ELIE GARDNER IN LIMA}

"Y ou go out to these communities that are so incredibly poor, and there is money buried in the dirt," says Jason Scullion. "It is not surprising that they want to go out there and dig it up."

Scullion, a graduate student in environmental and forest sciences at the University of Washington, Seattle, arrived in the Peruvian region of Madre de Dios last September, just after the price of gold hit a record high of US\$68 per gram. Madre de Dios is at ground zero of Peru's gold rush: an estimated 30,000 artisanal and small-scale miners work in this lush Amazonian area, one of the most biologically diverse places on Earth. Scientists and conservationists are alarmed by the damage that mining is causing to the land and its people.
In the 1930s, settlers armed with shovels, picks and pans came to search the riverbanks for deposits of gold washed down from the Andes mountains. Now, mechanical diggers and dump trucks are much more common. Peru is the sixth-largest producer of gold in the world, and the metal was its main export in the first quarter of this year. Yet about $20 \%$ of Peru's bullion is mined illegally, using techniques that destroy forests and pollute local rivers - as well as depriving the government of an estimated US $\$ 305$ million in taxes each year. The informal operations rarely assess their effects on the environment, or develop plans for what to do with the mines once they are exhausted, and they leave behind mountains of sand and rock, dead trees and deep pits filled with murky water.

Now the government is tightening the screws on illegal mining, and scientists monitoring its impacts are on the front lines of a battle between miners, environmental campaigners and the authorities.

In February, the Peruvian government banned mining in Madre de Dios outside a designated 500,000-hectare corridor (see map) and ordered that all miners must formally register - a year-long process that requires the mine operators to produce a work plan, an environmental-impact assessment and a clean-up strategy, among other requirements. By setting aside a specific area for mining, the government hopes to regulate the industry more effectively and to protect parks and the territories of indigenous people. But miners who have worked
ONATURE.COM For Nature's special on the changing Amazon, see: go.nature.com/pvnkj5 outside this newly designated corridor for decades with the government's tacit approval fear for their livelihoods, and the Madre de Dios 
Mining Federation in regional capital Puerto Maldonado has campaigned strongly against the legislation. In March, three people died as police clashed with federation-organized protests involving about 15,000 people. The government began raiding mining camps outside the corridor in late March, but in many of those areas miners have since returned to work.

Only around 4,000 miners in the region have met the government's deadline of 13 June to register their mining activities, suggesting that many more intend to disregard the order. Miners who have not registered, or who break environmental laws, will face up to 10 years in prison. But locals say that corruption and lack of government resources in Madre de Dios will make enforcing the law difficult.

\section{SPOILT WILDERNESS}

At stake are broad swathes of fertile rainforest, including that in the Tambopata National Reserve and Manu National Park, which is the largest national park in Peru and has been designated a World Heritage Site by the United Nations Educational, Scientific and Cultural Organization. "This is the epitome of a healthy ecosystem," says Enrique Ortiz, vice-president of the Amazon Conservation Association, based in Washington DC. "It's the capital of biodiversity." But mining is already beginning to encroach on these areas, and was threatening to become more widespread. A study published last year (J. J. Swenson et al. PLoS ONE 6, e18875; 2011) showed that mining is deforesting Madre de Dios faster than any other activity. Using satellite imagery, the study's authors found that deforestation in two prominent mining zones increased sixfold between 2003 and 2009, destroying 6,600 hectares of wetlands and primary tropical forest. And they predicted that the trend will only get worse.

Scullion came to Madre de Dios to find out whether that prediction is coming true. Funded by a 10-month grant from the US government's Fulbright Program, he is mapping 2 million hectares of the region, including many of the mining hotspots. Most previous mapping studies have assigned land to only two categories - forested and deforested - lumping agriculture, towns and mining areas together, and making it difficult to track the impact of the gold rush. Scullion's study will use ten categories, including mining, agriculture and five different classes of forestry.

Scullion says that there is a misconception among locals that researchers are against mining. Not so, he says - he just wants it to be done in a more sustainable way, staying out of parks and reserves, and ensuring that miners reforest areas after operations have finished. Scullion hopes that his maps will identify the most vulnerable areas in Madre de Dios, as well as the most biologically diverse, and says that they could provide the high-quality information that the government needs to decide whether land should be used for logging, mining or conservation. The data could also help to guide where - and how much - mining takes place in the designated corridor.

Mining is also taking its toll on local people. An estimated 45-50 tonnes of mercury are used each year in Madre de Dios to extract the prized gold, and a large proportion of that ends up in rivers or is released into the atmosphere.

Miners combine mercury with sediments that contain gold - typically using their feet to mix them in a bucket or drum - to form a solid amalgam of the two metals. That amalgam is then heated, often in frying pans over open flames in non-ventilated spaces, to boil off the mercury and leave gold behind.

In March, Katy Ashe, a graduate student in environmental engineering at Stanford University in California, published the first study (K. Ashe PLoS ONE 7, e33305; 2012) to show the scale of the health threat from mercury in Madre de Dios. She found that in mining zones, the proportion of people burdened with unhealthy levels of the metal -6 micrograms or more per gram of dry hair tested — was more than twice that in Puerto Maldonado. Mercury poisoning can cause vomiting and

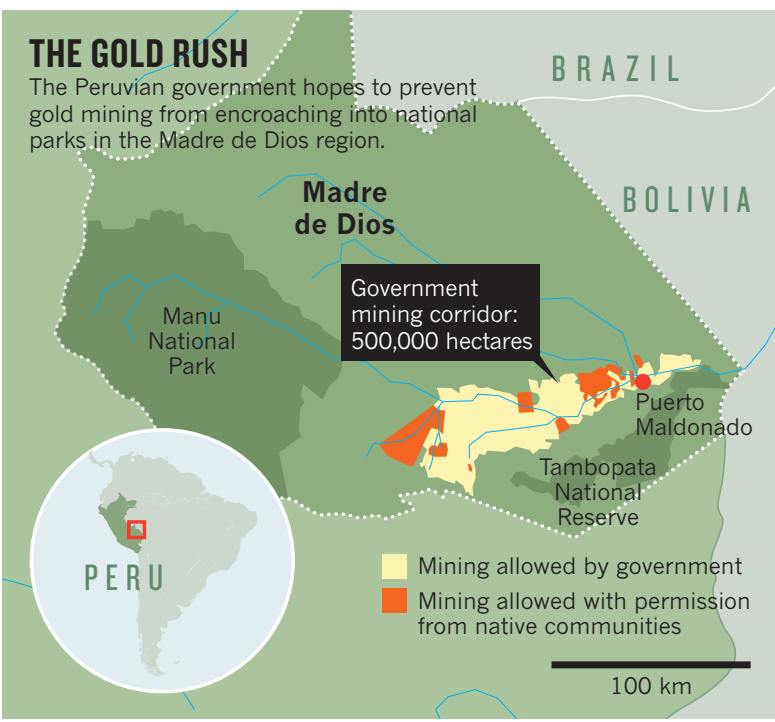

diarrhoea and, in more extreme cases, brain or kidney damage. Because the metal accumulates in rivers, elevated mercury levels were much more common in those who ate a lot of fish: $18 \%$ of people who ate 12 or more fish meals each month had unhealthy mercury levels, in contrast to just $6 \%$ and $7 \%$ of low and moderate fish consumers, respectively.

That finding tallies with as-yet unpublished research by Luis Fernandez, a tropical ecologist at the Carnegie Institution for Science in Stanford, with whom Ashe is about to begin working. In 2009, Fernandez discovered that the

most-consumed fish species in Madre de Dios, such as the mota (Calophysus macropterus) and doncella (Pseudoplatystoma fasciatum), had the highest levels of mercury. Fernandez is now leading a project to conduct a more extensive survey of the levels of mercury in fish and humans.

Despite the overwhelming evidence of harm, Peruvians are still divided over the findings. Some march through Puerto Maldonado's main plaza shouting through mega-

\section{"Mining is deforesting Madre de Dios faster than any other activity."} phones that mercury is killing everyone, whereas others are willing to drink the toxic liquid metal to prove it is safe.

Variations of the mercury-amalgamation technique have been used in gold mining for centuries, and it is difficult to dislodge such deep-rooted practices among artisanal miners. The global goldmining industry, including leading mines in Peru, has mostly switched to an extraction process that uses cyanide, and recovers about twice as much gold as does mercury amalgamation. But cyanide requires more careful handling than mercury and few artisanal or small-scale miners have the necessary knowledge and skills. The more modern process of thiosulphate leaching might offer a non-toxic alternative, but it is most effective with very fine particles of gold - and Madre de Dios tends to yield larger, coarser grains.

To reduce miners' exposure to mercury, non-governmental organizations have distributed retorts that can capture the toxic vapour. Two years ago, Peruvian engineer Carlos Villachica unveiled the ECO-100V, a US $\$ 4,500$ machine that uses water and jets of air to separate gold from sediments. And local development organizations such as Caritas Peru, based in Callao, and the Association for Integral Research and Development in Lima have developed other mercury-free technologies for extracting gold.

But Cesar Ascorra, director of Caritas Peru's office in Madre de Dios, says that miners will not switch methods unless the alternative works just as quickly, recovers at least as much gold, and is no more expensive than mercury amalgamation. For now, he adds, miners are more worried about the government's demands for them to formalize their work, and until the price of mercury goes up, or its use is banned, there is little incentive for them to change their practices.

Ortiz says that this underscores the value of research in the region - and the importance of disseminating the results through publicawareness campaigns. Studies such as Fernandez's are not done "for the sake of knowledge", says Ortiz. "This has a direction." 